\title{
RELATIONSHIPS BETWEEN COMPONENTS OF PHYSICAL ACTIVITY AND HEART RATE VARIABILITY IN OLDER WOMEN
}

\author{
Ligita Šilinė, Loreta Stasiulė, Arvydas Stasiulis, Renata Rutkauskaitė \\ Lithuanian Sports University, Kaunas, Lithuania
}

\begin{abstract}
Background. The level of daily activities of elderly persons decreases with aging. Also, reduced heart rate variability has been seen with normal aging. So, the aim of this study was to examine the relationships between physical activity and heart rate (HR) variability in older women.

Methods. Nine healthy women were invited to participate in this study (age $67.0 \pm 4.4$ ). HR variability was assessed during active orthostatic test; physical activity was assessed by accelerometer.

Results. Total physical activity was significantly correlated with mean HR $(r=-.73)$, RRI $(r=.73)$, RMSSD $(r=.83), \mathrm{HF}(r=.78), \mathrm{SD} 1(r=.78)$ and $\mathrm{SD} 1 / \mathrm{SD} 2(r=.72)$ in supine position. In addition total physical activity was significantly correlated with mean HR $(r=-.68), \operatorname{RMSSD}(r=.80)$, LF $(r=.87), \mathrm{HF}(r=.83)$, SD1 $(r=.82)$, SD2 $(r=.65)$ and $\mathrm{SD} 1 / \mathrm{SD} 2(r=.72)$ in standing position.

Conclusion. Total physical activity is positively associated with higher heart rate variability in older women.
\end{abstract}

Keywords: physical activity, heart rate variability, older women.

\section{INTRODUCTION}

$\mathrm{T}$ The number of people older than 60 years is increasing. The aging process leads to reduced physical fitness and results in difficulties in daily life activities and normal functioning of the elderly. The level of daily activities of elderly persons decreases with aging. Physical activity is important for independent living, prevention of chronic health problems, and quality of life (Milanovic et al., 2013).

Cardiorespiratory fitness is important for endurance exercise performance. Low cardiorespiratory fitness is related to the development of the metabolic syndrome, the progression of atherosclerosis and coronary arterial disease and may account for $16 \%$ of all deaths (Ramsbottom, Currie, \& Gilder, 2010). Accelerometers are widely accepted as valid objective measures of physical activity, and the ActiGraph is the most commonly used brand (Cain, Conway, Adams, Husak, \& Sallis, 2013). Heart rate variability (HRV) is a non-invasive technique for estimating the characteristics of the autonomic nervous system and for quantifying modulation of the sympathetic and parasympathetic inputs. Low HRV may be indicative of disturbed cardiac autonomic activity, in particular excessive sympathetic and/or inadequate parasympathetic activity. Reduced HRV is related to increased risk of cardiac events and all-cause mortality (Jandackova \& Jackowska, 2015).

We hypothesized that heart rate variability would be associated with physical activity. The aim of this study was to determine the relationship between components of physical activity and heart rate variability in older women.

\section{METHODS}

The present study received the approval of Kaunas Regional Biomedical Research Ethics Committee. All participants signed a statement of 
Table 1. Characteristics of participants

\begin{tabular}{|c|c|c|c|c|c|c|c|c|}
\hline $\begin{array}{c}\text { Participant } \\
(n=9)\end{array}$ & Age & Height (cm) & $\begin{array}{c}\text { Weight } \\
\mathbf{( k g})\end{array}$ & $\begin{array}{c}\text { Body mass } \\
\text { index }\end{array}$ & $\begin{array}{c}\text { Fat mas } \\
(\mathbf{k g})\end{array}$ & $\begin{array}{c}\text { Fat mass } \\
\mathbf{( \% )}\end{array}$ & FFM (kg) & $\begin{array}{c}\text { V. } \dot{\boldsymbol{O}}_{2 \max } \\
(\mathbf{m l} / \mathbf{k g} / \mathbf{m i n})\end{array}$ \\
\hline Mean & 67.0 & 160.3 & 67.7 & 26.4 & 24.0 & 35.0 & 43.7 & 14.3 \\
\hline SD & 4.4 & 5.7 & 10.2 & 3.4 & 6.8 & 4.3 & 4.1 & 5.4 \\
\hline
\end{tabular}

informed consent after receiving both written and verbal information as to the nature and purpose of the experiment. The study was performed in the Lithuanian Sports University.

Of the 11 volunteers recruited to the study, 9 of them completed it. All participants were women, non-smokers. Exclusion criteria included type I or II diabetes, hypertension, any known heart disease, asthma or any respiratory restrictive problem, muscular skeletal injury.

Pre-test information sheets required the participants to abstain from caffeine-containing beverages $2-3 \mathrm{~h}$ before testing heart rate variability. Volunteers were also asked to refrain from alcohol and participation in vigorous exercise for $24 \mathrm{~h}$ prior to measurement of HRV.

Anthropometry. Height was measured in centimeters using an upright stadiometer. Participants stood barefoot with their heels and head in contact with the wall and arms at their sides. Weight, fat mass and FFM were measured in kilograms using a body composition analyzer (Tanita BC-418MA). Body mass index (BMI) was calculated using the equation: $\mathrm{BMI}=$ weight $(\mathrm{kg}) /$ height $(\mathrm{m})^{2}$ (Tomaz, Lambert, Karpul, \& KolbeAlexander, 2016).

Cardiorespiratory fitness $\left(\mathrm{VO}_{2 \max }\right)$ was estimated by University of Houston Non-Exercise Test (BMI Model). Subjects had to determine their physical activity rating from 1 to 7 (PAR) using test table. $\mathrm{VO}_{2 \max }$ was calculated using the equation: $\mathrm{VO}_{2} \max (\mathrm{ml} / \mathrm{kg} / \mathrm{min})=56.363-(.381 \mathrm{x}$ age (years) $)-(.754 \times$ BMI $)+(1.951 \times$ PAR) (Kelley, Lowing, \& Kelley, 1999).

HRV was measured using active orthostatic test. HR was determined for 5 minutes with the patients in the supine posture. Thereafter, subjects actively stood up, maintaining upright posture quietly for 5 minutes. Prior to the active orthostatic test subjects were instructed to stand quickly and independently. All subjects stood up within 3-4 seconds.

HR was recorded using a Polar S810i heart rate monitor. Analysis of heart rate variability was via a software program (Polar Precision Performance), which calculated time- and frequency-domain measures. The main time domain variables investigated were SDNN (ms) (standard deviation of all normal-to-normal intervals) and RMSSD (ms) (the square root of the mean of the sum of the squares of differences between adjacent normal-to-normal intervals). The main frequency-domain variables investigated were low frequency power (LF power, $\left.\mathrm{m} \cdot \mathrm{s}^{-2}\right)$, power in the low-frequency range $(0.04$ $0.15 \mathrm{~Hz}$ ), high-frequency power (HF power, $\mathrm{m} \cdot \mathrm{s}^{-2}$ ), power in the high frequency range $(0.15-0.4 \mathrm{~Hz})$, and the low-frequency/high-frequency (LF/HF) ratio, which is thought to reflect the relative proportions of ventilatory and baroreceptor modulation of heart rate variability (Ramsbottom et al., 2010). Poincare' variables were also derived from the R-R interval data, namely $\mathrm{SD}_{1}$, a measure of the instantaneous beat-to-beat variability, and $\mathrm{SD}_{2}$, thought to quantify long-term heart rate variability, as well as the ratio $\mathrm{SD}_{1} / \mathrm{SD}_{2}$ or Poincare' dimension, thought to reflect non-linear components of heart rate variability (Mourot et al., 2004).

Accelerometry. The tri-axial ActiGraph GT3X accelerometer (Tri-axis ActiTrainer Activity Monitor) was used in this study. The device was set to measure motion in all three axes and was set to record data in 60-second epochs. Accelerometer data were captured and cleaned using the ActiLife Software. Data from all three axes were captured and used in the analysis. The accelerometer was given to the participants after the active orthostatic test, and physical active questionnaire, and participants were requested to maintain their usual activity levels while wearing the device. Participants were requested to wear the accelerometer on their right hip for seven consecutive days, but not while bathing, showering or swimming. A minimum of 4 days of wear, with 600 minutes per day were required for data analysis. Non-wear time was defined as 60 continuous minutes of no counts (zeros). Moderate, light and sedentary intensity physical activity levels were estimated based on accelerometer counts using the cut-off points. Counts between 1952 and 5724 (inclusive) represents moderate to vigorous intensity PA (MVPA), counts between 
100 and 1951 (inclusive) represent light activity, and counts below $100(0-100)$ represent sedentary activity (Keadle, Shiroma, Freedson, \& Lee, 2014).

Statistical analysis was carried out using Microsoft Excel (2010) and SPSS (Version 17). Kolmogorov-Smirnov test was used to check for normality of data $(p>.05)$. The strength of the association between variables was assessed by Spearman's product - moment correlation coefficient.

\section{RESULTS}

Participants self-reported low physical activity, from which cardiorespiratory fitness $\left(\mathrm{VO}_{2} \mathrm{max}\right)$ was calculated. There was no significant correlation between estimated $\mathrm{VO}_{2} \max$ and physical activity components (Table 1,2). The highest correlation was found between total physical activity and RMSSD $(r=.83)$. Also significant correlation was estimated between total physical activity and high-frequency power $(r=.78)$, and SD1 $(r=.78)$ (Table 1).

Table 2. Spearman's correlations between components of physical active, cardiorespiratory fitness and heart rate variability in supine position

\begin{tabular}{|c|c|c|c|c|c|}
\hline & Steps/day & Total activity & Moderate PA & Light PA & Sedentary PA \\
\hline $\mathrm{VO}_{2} \max (\mathrm{ml} / \mathrm{min} / \mathrm{kg})$ & .05 & .12 & .05 & .13 & -.22 \\
\hline HR average (beats/min) & -.38 & $-.73^{*}$ & -.23 & -.17 & .20 \\
\hline HR supine (beats/min) & -.42 & $-.72 *$ & -.37 & -.43 & .47 \\
\hline RMSSD (ms) & .52 & $.83^{*}$ & .35 & $.75^{*}$ & $-.82 *$ \\
\hline $\mathrm{LF}\left(\mathrm{m} \cdot \mathrm{s}^{-2}\right)$ & .57 & .43 & .57 & .22 & -.22 \\
\hline $\mathrm{HF}\left(\mathrm{m} \cdot \mathrm{s}^{-2}\right)$ & .42 & $.78^{*}$ & .25 & $.70 *$ & $-.73^{*}$ \\
\hline $\mathrm{LF} / \mathrm{HF}$ ratio & .18 & -.05 & .33 & -.12 & .13 \\
\hline SD1 & .42 & $.78^{*}$ & .25 & $.70^{*}$ & $-.73^{*}$ \\
\hline $\mathrm{SD} 2$ & $.62 *$ & .45 & $.67^{*}$ & .52 & -.53 \\
\hline SD1/SD2 & .35 & $.72 *$ & .17 & $.60^{*}$ & $-.63^{*}$ \\
\hline
\end{tabular}

Notes. *Significant at $p<.05$

Time domain analysis: SDNN, standard deviation of the R-R intervals; RMSSD, square root of the mean of the sum of the squares of the differences between adjacent R-R intervals. Frequency domain analysis (autoregression analysis): LF, low-frequency power (0.04-0.15 Hz); HF, high-frequency power $(0.15-0.40 \mathrm{~Hz})$; LF/HF, low-frequency/high-frequency power ratio. SD1, short axis of the Poincare' plot; SD2, long axis of the Poincare' plot; SD12, the ratio SD1/SD2 or Poincare' dimension.

Table 3. Spearman's correlations (rs) relationships between components of physical active, cardiorespiratory fitness and heart rate variability during standing position

\begin{tabular}{|c|c|c|c|c|c|}
\hline & Steps/day & Total activity & Moderate PA & Light PA & Sedentary PA \\
\hline $\mathrm{VO}_{2} \max (\mathrm{ml} / \mathrm{min} / \mathrm{kg})$ & .05 & .12 & .05 & .13 & -.22 \\
\hline HR average (beats/min) & -.38 & $-.68 *$ & -.23 & -.17 & .20 \\
\hline HR standing (beats/min) & -.13 & -.53 & -.20 & $-.67 *$ & $.62 *$ \\
\hline RMSSD (ms) & $.68^{*}$ & $.80^{*}$ & .44 & .27 & -.43 \\
\hline $\mathrm{LF}\left(\mathrm{m} \cdot \mathrm{s}^{-2}\right)$ & $.82 *$ & $.87^{*}$ & $.63 *$ & .43 & -.53 \\
\hline $\mathrm{HF}\left(\mathrm{m} \cdot \mathrm{s}^{-2}\right)$ & $.67 *$ & $.83 *$ & .40 & .40 & -.52 \\
\hline $\mathrm{LF} / \mathrm{HF}$ ratio & -.10 & -.23 & .17 & .02 & .10 \\
\hline SD1 & $.70^{*}$ & $.82 *$ & .47 & .30 & -.45 \\
\hline $\mathrm{SD} 2$ & .48 & $.65^{*}$ & .22 & .25 & -.35 \\
\hline SD1/SD2 & $.58 *$ & $.72 *$ & .33 & .38 & -.52 \\
\hline
\end{tabular}

Notes. *Significant at $p<.05$

Time domain analysis: SDNN, standard deviation of the R-R intervals; RMSSD, square root of the mean of the sum of the squares of the differences between adjacent R-R intervals. Frequency domain analysis (autoregression analysis): LF, low-frequency power (0.04-0.15 Hz); HF, high-frequency power $(0.15-0.40 \mathrm{~Hz})$; LF/HF, low-frequency/high-frequency power ratio. SD1, short axis of the Poincare' plot; SD2, long axis of the Poincare' plot; SD12, the ratio SD1/SD2 or Poincare' dimension. 
In standing position heart rate variability components are more expressed. There was found a significant correlation between the number of steps per day and low-frequency power LF $(r=.82)$. Total activity was significantly correlated with HR average $(r=-.68)$, RMSSD $(r=.8)$, low-frequency power LF $(r=.87)$ and high-frequency power HF $(r=.83)$, SD1 $(r=.82), \mathrm{SD} 2(r=.65)$ and SD1/SD2 $(r=.72)$ (Table 3).

\section{DISCUSSION}

The main finding of this study is that heart rate variability is associated with physical activity in older women. We found positive significant correlation between total physical activity and many heart rate variability components both in supine and standing positions.

Objective information on the physical activity levels and sedentary behavior has the potential to increase our understanding of physical activity in older age. The introduction of accelerometers for objective assessment of physical activity allows for valid and reliable assessments of activity intensity, frequency, and duration. It has been established that women demonstrate significantly more minutes of low-intensity physical activity than men (LohneSeiler, Hansen, Kolle, \& Anderssen, 2014).

The most frequently used heart rate variability parameters are the frequency-domain (high and low frequency ratio), time-domain (SD, SDNN, RMSSD), and Poincaré plot (SD1, SD2) parameters (Makivic, Djordjevic Nikic, \& Willis, 2013). Cardiac diseases and arrhythmias are common with aging. It has been established that walking at least $1.0 \mathrm{~h}$ or more per week was associated with $>50 \%$ reduction in coronary heart disease risk in multivariate models (Lee, Rexrode, Cook, Manson, \& Buring, 2001). Women $(n=88,393)$ who were moderately active $(1-3.49 \mathrm{~h} /$ week $)$ and active $(\geq 3.5 \mathrm{~h} /$ week), had $43 \%$ and $58 \%$ lower risk of coronary heart disease, respectively, compared to sedentary women ( $<1 \mathrm{~h} /$ week) (Li et al., 2006). Increasing the level of physical activity was associated with a $36 \%$ reduction in cardiovascular mortality in sedentary older women (Swift et al., 2013).

We found a significant negative correlation between total physical activity and HR average, which means that physical activity is associated with increased parasympathetic activity. In middle-aged populations, habitual physical activity has been associated with more favorable HRV indices, especially those reflecting increased vagal modulation and reduced sympathetic activity. Older adults have much higher risk for abnormal HRV and cardiac events than middle-aged populations (Soares-Miranda et al., 2014). HRV parasympathetic activity decreases faster until the age of 80 years and then starts to increase again (Reardon \& Malik, 1996).

Lots of studies have identified the effects of exercise on enhancing vagal tone. Poor physical fitness is associated with impairment in cardiac vagal function during exercise (Makivic et al., 2013). Greater total leisure time activities, as well as walking alone, were prospectively associated with healthier cardiac autonomic function (Poirier, 2014). In our study, total physical activity was significantly correlated with HRV time domain (RMSSD), frequency-domain (high and low frequency rates) and Poincaré plot (SD1, SD2 and SD1/SD2). It has been established that HRV depends on leisure - time activity, walking distance and speed. Those participants who had increased walking speed had significantly higher SDNN in comparison with those that decreased or maintained their walking speed. Similarly, those that increased walking speed had significantly higher normalized low-frequency power, low frequency/high frequency ratio and less irregular HRV in comparison with those that decreased or maintained their walking speed. Additionally, those that increased walking speed had lower normalized high-frequency power in comparison with those that maintained or decreased their walking speed (Soares-Miranda et al., 2014).

Physical activity is associated with a more favorable HRV profile (Borghi-Silva et al., 2009). The specific associations with indices that might reflect circadian variation (SDNN and ultra-low frequency power (ULF)), combined activity of sympathetic and parasympathetic modulation (normalized low-frequency power), vagal control of heart rate and also renin-angiotensin system neurohormonal modulation (very-low-frequency power), and less abnormal HR patterns (Poincaré ratio suggests relatively selective effects of physical activity on the biological pathways influencing these parameters). Although the biological interpretation of these indices is complex (e.g. SDNN and ULF may reflect multiple inputs beyond circadian variation), physical activity is not related to all HRV indices similarly in older adults (Soares-Miranda et al., 2014). 
Regularly performed physical activity is associated with a reduced risk of cardiovascular disease, some forms of cancer, and all-cause mortality (Orsini et al., 2008). Reduction in sympathetic activity and increased vagal activity has been implicated as possible pathways by which regular physical activity provides cardio protective benefits (Carter, Banister, \& Blaber, 2003). Physical activity may also directly affect cardio myocytes by leading to improved contractile capacity (Wisløff, Ellingsen, \& Kemi, 2009), and by enhancing cardiac electric stability (Billman, 2009). Also, physical activity may reduce arrhythmic, myocardial infarction and heart failure risk in humans (SoaresMiranda et al., 2014).

HRV modulation depends on body fat (Poliakova et al., 2012; Salamin et al., 2013). Aging is associated with decreased muscle mass and increased fat mass, particularly visceral fat. Abnormal HRV has been associated with the severity of left ventricular diastolic dysfunction (Poirier et al., 2003), which has been associated with lower exercise capacity (Poirier et al., 2000).

Regular physical activity in older adults is very important for healthy aging (Lohne-Seiler et al., 2014). Women taking 7,500-9,999 steps/day had significantly lower BMI and percent body fat than women taking $<5,000$ steps/day. The steps range for healthy older adults is recommended 7,000$10,000 \mathrm{steps} /$ day, at least 3,000 of which should be accumulated at a brisk pace (Tudor-Locke et al., 2011). In our study, women were taking about 7662 steps/day. Increasing PA (expressed as energy per week) is positively related to reductions in total adiposity, and the effects occur in a dose-response manner. A protective effect of physical activity on site-specific cancer risk, with a dose-response association between physical activity and colon and pre-and postmenopausal breastcancer, has also been suggested by the particular biological mechanisms that are responsible for the development of these diseases (Pelclova, Gaba, Tlucakova, \& Pospiech, 2012). We found significant correlation between steps per day number and RMSSD, LF, HF, SD1, SD1/SD2. Walking 10,000 steps/day or more for 12 weeks was effective at lowering sympathetic nerve activity, but ineffective on parasympathetic nerve activity, baroreceptor reflex sensitivity, BMI, lipids, and glucose tolerance (Iwane et al., 2000).

\section{CONCLUSION}

In conclusion, we estimated significant correlation between physical activity and heart rate variability in older women. More physically active older women demonstrated higher HRV during orthostatic test. Physical activity proved to be very important for normal cardiac autonomic function in older women.

\section{REFERENCES}

Billman, G. E. (2009). Cardiac autonomic neural remodeling and susceptibility to sudden cardiac death: effect of endurance exercise training. American Journal of Physiology and Heart Circulation Physiology, 297(4), 1171-1193. doi: 10.1152/ajpheart.00534.2009

Borghi-Silva, A., Arena, R., Castello, V., Simões, R. P., Martins, L. E., Catai, A. M., \& Costa, D. (2009). Aerobic exercise training improves autonomic nervous control in patients with COPD. Respiratory Medicine, 103(10), 1503-1510. doi: 10.1016/j.rmed.2009.04.015

Cain, K., Conway, T., Adams, M., Husak, L., \& Sallis, J. (2013). Comparison of older and newer generations of ActiGraph accelerometers with the normal filter and the low frequency extension. International Journal of Behavioral Nutrition and Physical Activity, 10(51), 1-6. doi: 10.1186/1479-5868-10-51

Carter, J. B., Banister, E. W., \& Blaber, A. P. (2003). Effect of endurance exercise on autonomic control of heart rate. Sports Medicine, 33(1), 33-46.

Iwane, M., Arita, M., Tomimoto, S., Satani, O., Matsumoto, M., Miyashita, K., \& Nishio, I. (2000).
Walking 10,000 steps/day or more reduces blood pressure and sympathetic nerve activity in mild essential hypertension. Hypertension Research, 23(6), 573-580.

Jandackova, V. K., \& Jackowska, M. (2015). Low heart rate variability in unemployed men: The possible mediating effects of life satisfaction. Psychology, Health \& Medicine, 20(5), 530-540. doi: 10.1080/13548506.2014.987148

Keadle, S. K., Shiroma, E., Freedson, P. S., \& Lee, I. (2014). Impact of accelerometer data processing decisions on the sample size, wear time and physical activity level of a large cohort study. BioMed Central Public Health, 14(1210), 1-8. doi: 10.1186/1471-2458-14-1210 Kelley, G. A., Lowing, L., \& Kelley, K. (1999). Gender differences in the aerobic fitness levels of young AfricanAmerican adults. Journal of the National Medical Association, 91(7), 384-388.

Lee, I. M., Rexrode, K. M., Cook, N. R., Manson, J. E., \& Buring, J. E. (2001). Physical activity and coronary heart disease in women: Is "no pain, no gain" passé? The Journal of the American Medical Association, 285(11), 1447-1454. 
Li, T. Y., Rana, J. S., Manson, J. E., Willett, W. C., Stampfer, M. J., Colditz, G. A., ... Hu, F. B. (2006). Obesity as compared with physical activity in predicting risk of coronary heart disease in women. Circulation, 113(4), 499-506. doi:10.1161/ CIRCULATIONAHA.105.574087

Lohne-Seiler, H., Hansen, B. H., Kolle, E., \& Anderssen, S. (2014). Accelerometer-determined physical activity and self-reported health in a population of older adults (65-85 years): A cross-sectional study. BioMed Central Public Health, 14, 284, 1-10. doi: 10.1186/14712458-14-284

Makivic, B., Djordjevic Nikic, M., \& Willis, M. S. (2013). Heart rate variability (HRV) as a tool for diagnostic and monitoring performance in sport and physical activities. Journal of Exercise Physiology, 16(3), 103-131.

Milanovic, Z., Pantelic, S., Trajkovic, N., Sporis, G., Kostic, \& James, N. (2013). Age-related decrease in physical activity and functional fitness among elderly men and women. Clinical Interventions in Aging, 8, 549-556. doi: 10.2147/CIA.S44112

Mourot, L., Bouhaddi, M., Perrey, S., Cappelle, S., Henriet, M.-T., Wolf, J. P., ... Regnard, J. (2004). Decrease in heart rate variability with overtraining: Assessment by the Poincare' plot analysis. Clinical Physiology and Functional Imaging, 24(1), 10-18.

Orsini, N., Bellocco, R., Bottai, M., Hagstromer, M., Sjostrom, M., Pagano, M., \& Wolk, A. (2008). Validity of self-reported total physical activity questionnaire among older women. European Journal of Epidemiology, 23(10), 661-667. doi: 10.1007/s10654-008-9273-z

Pelclova, J., Gaba, A., Tlucakova, L., \& Pospiech, D. (2012). Association between physical activity (PA) guidelines and body composition variables in middleaged and older women. Archives of Gerontology and Geriatrics, 55(2), 14-20. doi: 10.1016/j. archger.2012.06.014

Poirier, P., Bogaty, P., Philippon, F., Garneau, C., Fortin, C., \& Dumesnil, J. G. (2003). Preclinical diabetic cardiomyopathy: Relation of left ventricular diastolic dysfunction to cardiac autonomic neuropathy in men with uncomplicated well-controlled type 2 diabetes. Metabolism, 52(8), 1056-1061.

Poirier, P. (2014). Exercise, heart rate variability, and longevity: The cocoon mystery? Circulation, 129(21), 20852087. doi: 10.1161/CIRCULATIONAHA.114.009778

Poirier, P., Garneau, C., Bogaty, P., Nadeau, A., Marois, L., Brochu, C., ... Dumesnil, J. G. (2000). Impact of left ventricular diastolic dysfunction on maximal treadmill performance in normotensive subjects with well-controlled type 2 diabetes mellitus. The American Journal of Cardiology, 85(4), 473-477.

Poliakova, N., Despres, J. P., Bergeron, J., Almeras, N., Tremblay, A., \& Poirier, P. (2012). Influence of obesity indices, metabolic parameters and age on cardiac autonomic function in abdominally obese men. Metabolism, 61(9), 1270-1279. doi: 10.1016/j. metabol.2012.02.006

Ramsbottom, R., Currie, J., \& Gilder, M.(2010). Relationships between components of physical activity, cardiorespiratory fitness, cardiac autonomic health, and brainderived neurotrophic factor. Journal of Sports Sciences, 28(8), 843-849. doi: 10.1080/02640411003702686

Reardon, M., \& Malik, M. (1996). Changes in heart rate variability with age. Pacing and Clinical Electrophysiology, 11(2), 1863-1866.

Salamin, G., Pelletier, C., Poirier, P., Despres, J. P., Bertrand, O., Almeras, N., ... Brassard, P. (2013). Impact of visceral obesity on cardiac parasympathetic activity in type 2 diabetics after coronary artery bypass graft surgery. Obesity (Silver Spring), 21(8), 1578-1585. doi: 10.1002/oby.20089

Soares-Miranda, L., Sattelmair, J., Chaves, P., Duncan, G., Siscovick, D. S., Stein, P. K., \& Mozaffarian, D. (2014). Physical activity and heart rate variability in older adults: The cardiovascular health study. Circulation, 41(1), 2100-2121. doi: 10.1161/ CIRCULATIONAHA.113.005361

Swift, D. L., Lavie, C. J., Johannsen, N. M., Arena, R., Earnest, C., O'Keefe, ... Church, T. S. (2013). Physical activity, cardiorespiratory fitness, and exercise training in primary and secondary coronary prevention. Circulation Journal, 77(2), 281-292.

Tomaz, S. A., Lambert, E. V., Karpul, D., \& KolbeAlexander, T. L. (2016). Cardiovascular fitness is associated with bias between self-reported and objectively measured physical activity. European Journal of Sport Science, 16(1), 149-157. doi: 10.1080/17461391.2014.987323

Tudor-Locke, C., Craig, C., Aoyagi, Y., Bell, R., Croteau, K., Bourdeaudhuij, I., ... Blair, S. (2011). How many steps/day are enough? For older adults and special populations. International Journal of Behavioral Nutrition and Physical Activity, 8(80), 1-19. doi: 10.1186/1479-5868-8-80

Wisløff, U., Ellingsen, Ø., \& Kemi, O. J. (2009). Highintensity interval training to maximize cardiac benefits of exercise training? Exercise Sport Science Review, 37(3), 139-146. doi: 10.1097/JES.0b013e3181aa65fc 